\title{
Invasive solid papillary carcinoma with neuroendocrine differentiation of the breast: a case report and literature review
}

\author{
Xue Lin ${ }^{1,2^{*}}$ (D), Yoshiaki Matsumoto ${ }^{2}$, Tomomi Nakakimura ${ }^{1}$, Kazuo Ono ${ }^{3}$, Shigeaki Umeoka ${ }^{4}$, Masae Torii ${ }^{1}$, \\ Hiroshi Yoshibayashi ${ }^{1}$ and Masakazu Toi ${ }^{2}$
}

\begin{abstract}
Background: Solid papillary carcinoma (SPC) of the breast is a rare breast cancer that accounts for less than 1\% of all breast cancers. The optimal clinical management of SPC remains controversial. Here, we report a case of invasive SPC with neuroendocrine differentiation in addition to review of the current literature.

Case presentation: A premenopausal 46-year-old female presented with a mass in her left breast that tended to increase in size over a 10-month period. Mammography and ultrasonography revealed a mass in the left upperinner quadrant. The resulting images suggested a category 3 breast tumor according to the Breast Imaging Reporting and Data System (BI-RADS). A core needle biopsy (CNB) was performed, and the pathological findings showed a solid papillary pattern and atypical cells suggestive of noninvasive SPC. After a left partial mastectomy and sentinel lymph node biopsy (SLNB), the specimens were sent for histopathological analysis for further investigation. Postoperative pathological findings suggested invasive SPC. Whole-breast radiation therapy and adjuvant hormonal therapy were performed as postoperative treatments. Three years after surgery, multiple lung metastases were detected, and the patient was treated with a gonadotropin-releasing hormone agonist and an aromatase inhibitor. Five months later, multiple liver metastases and bone metastases appeared, and oral 5fluorouracil was chosen for the subsequent treatment. The patient has been treated for 5 years to date, and she is continuing to take oral 5 -fluorouracil and is alive without any further disease progression.

Conclusions: We report a rare case of premenopausal invasive SPC with multiple metastases. Further study is needed to clarify the molecular characteristics and clinical behaviors of SPC and to explore the optimal treatment strategy.
\end{abstract}

Keywords: Invasive solid papillary carcinoma, Neuroendocrine differentiation, Breast, Metastasis

\section{Background}

Solid papillary carcinoma (SPC) is a rare mammary papillary lesion that is difficult to pathologically diagnose $[1,2]$ and was first reported in 1995 by Maluf and Koerner [3]. SPC is a low-grade breast tumor that originates from expanded ducts and comprises morphologically well-

\footnotetext{
* Correspondence: xuelin@kuhp.kyoto-u.ac.jp

${ }^{1}$ Department of Breast Surgery, Japanese Red Cross Wakayama Medical

Center, 4-20 Komatsubara-dori, Wakayama 640-8558, Japan

${ }^{2}$ Department of Breast Surgery, Kyoto University Hospital, 54 Kawaharacho,

Syogoin, Sakyo-ku, Kyoto 606-8507, Japan

Full list of author information is available at the end of the article
}

circumscribed solid nodules separated by fibrovascular cores $[1,2,4]$. SPC is a rare disease that mainly affects postmenopausal women; indeed, it is relatively rare for a woman to be affected before the age of 50 , and the average age of diagnosis with SPC is approximately 70 years old [1-6]. Although SPC is considered to be carcinoma in situ by the latest WHO classification, some studies have suggested that SPC is actually an invasive cancer because of the absence of myoepithelial cells at the tumor periphery $[2,7,8]$. SPC accounts for approximately $1 \%$ of all breast cancers. At the time of diagnosis, approximately $90 \%$ of cases are localized lesions, $8 \%$ involve lymph node 
metastases, and less than $0.4 \%$ present with distant metastases $[2,8,9]$. In this article, we report a case of a 46-yearold patient with invasive SPC who developed multiple distant metastases 3 years after surgery.

\section{Case presentation}

A 46-year-old woman received a mammogram, which showed a high-density mass less than $10 \mathrm{~mm}$ in her left breast. Subsequent breast ultrasonography (US) showed a well-demarcated and low-echogenic mass that measured $8 \mathrm{~mm}$ in the left upper-inner quadrant.

The results of the initial mammography and repeated US at her family clinic revealed that the mass had increase in size at a 10-month follow-up, and the patient was subsequently referred to our hospital. Mammography (Fig. 1a-d) and US (Fig. 1e) were repeated, and the US findings confirmed an increased mass size with abundant blood flow suggestive of a malignant tumor. Contrast-enhanced MRI demonstrated an ill-demarcated mass that measured $8 \mathrm{~mm} \times 7 \mathrm{~mm}$ in the $A$ area of the left breast (Fig. 1f). There were no apparent daughter lesions, intraductal findings, or lymph node swelling. The core needle biopsy (CNB) pathology showed clusters of atypical cells proliferating in solid and papillary patterns with a high nucleocytoplasmic (N/C) ratio (Fig. 2a, b). In addition, immunohistochemistry was performed with various monoclonal antibodies to confirm the diagnosis. The tumor was ER positive (Fig. 2c) and PgR negative. Regarding neuroendocrine markers, the SPC cells were positive for neuron-specific enolase (NSE), chromogranin, and synaptophysin (Fig. 2d-f), and negative for CD56 and S-100p antibodies. There were no myoepithelial cells on the outer edge of the tumor; this was confirmed by negative immunohistochemical (IHC) staining for myoepithelial markers, which included CD10, p63 (Fig. $2 \mathrm{~g}$ ), and $\alpha$-smooth muscle actin. No invasive carcinoma was found. Considering the imaging and histology findings together, the preoperative diagnosis of the tumor was neuroendocrine SPC, and its stage was cTiscNOM0.
The patient underwent a partial mastectomy of the left breast with sentinel lymph node biopsy (SLNB). For further confirmation, the specimens were sent for histopathological analysis (Fig. 3a), which showed wellcircumscribed solitary nodules with neuroendocrine components. Microscopic observation revealed dilated ducts filled with a high proportion of proliferating cells that contained a necrotic vascular stroma. Some tubelike structures were also observed, and these findings corresponded with SPC. The HE-stained sections suggested an obvious infiltration pattern, with a distribution that spread out from the lobular unit. Invasion was observed as irregularly shaped tumor nests that invaded the surrounding stroma (Fig. 3b, c). The tumor was 8 $\mathrm{mm} \times 7 \mathrm{~mm}$ in size, and the final diagnosis was SPC with invasion and massive SPC in situ.

In the immunohistochemical analysis, tumor cells were positive for NSE, chromogranin, and synaptophysin, which suggested that the tumor had a neuroendocrine feature. The myoepithelial markers CD10, P63, and $\alpha$ smooth muscle actin were negative. Postoperative pathological findings suggested SPC with invasion. The tumor had an ER-positive, PgR-negative, and HER2-negative biological phenotype, while the Ki-67 labeling index was approximately $30 \%$. The tumor exhibited an intermediate nuclear grade (grade II: $3-2-2$ ) in the invasive components, and the stage was $\mathrm{pT} 1 \mathrm{~b}(8 \mathrm{~mm}) \mathrm{pNO}(0 / 2, \mathrm{sn}) \mathrm{M} 0$, pStage I.

The postoperative treatment plan was determined based on the pathological diagnosis. Whole-breast radiation therapy followed by hormonal therapy (tamoxifen and a gonadotropin-releasing hormone ( $\mathrm{GnRH}$ ) agonist) was performed as adjuvant therapy. Three years after surgery, the patient developed a persistent cough with the absence of an inflammatory response, and a PET-CT examination showed multiple lung metastases. Systemic treatment was changed to a combination of an aromatase inhibitor and a GnRH agonist. Nevertheless, the metastatic tumors were aggressive, sizes of pulmonary lesions increased, and new liver and bone metastases

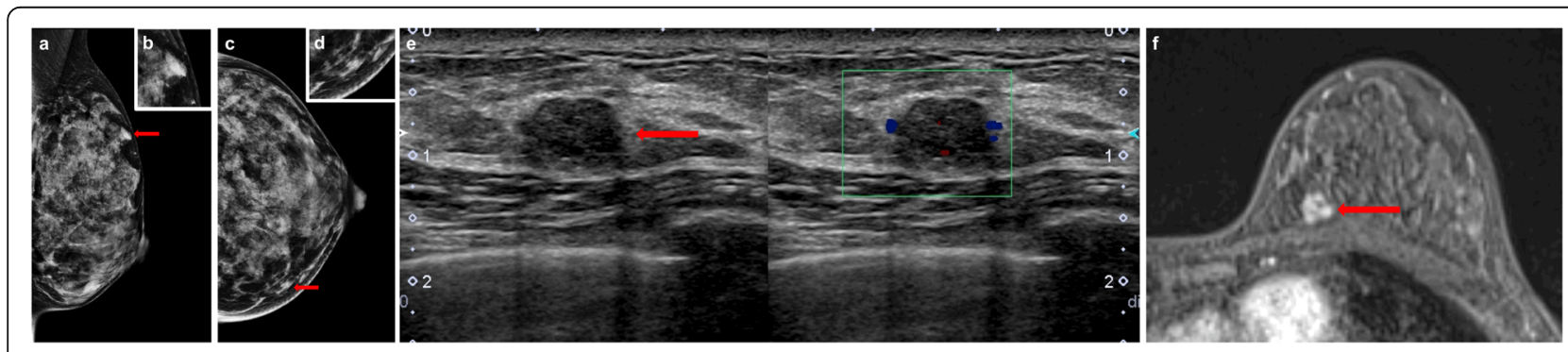

Fig. 1 Imaging findings. Mammogram showing a round, high-density mass in the left MLO-M area (a) and CC-I area (c). b, d Enlargements of the areas are indicated by red arrows. US shows a regular, circumscribed, hypoechoic, homogenous lesion with abundant blood flow in the A area of the left breast (e). Dynamic MRI demonstrates an ill-demarcated mass that measures $8 \mathrm{~mm} \times 7 \mathrm{~mm}$ in the A area of the left breast (f) without daughter lesions or enlarged lymph nodes 

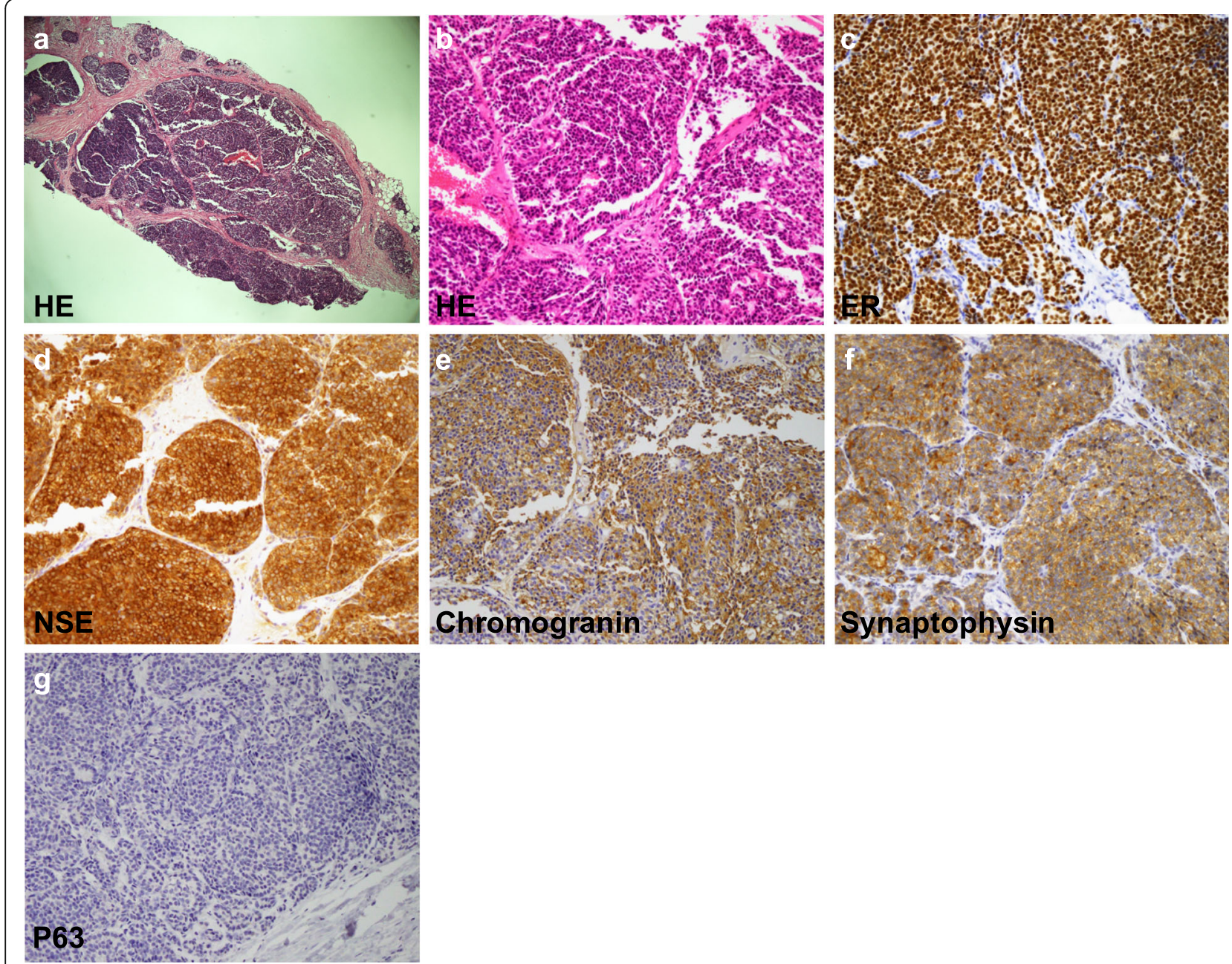

Fig. 2 Core needle biopsy histological findings of the tumor (a) and (b) HE-stained sections at $\times 4$ and $\times 20$ magnification. a Low-power view illustrates a solid papillary carcinoma. $\mathbf{b}$ High-power view demonstrates the rosette structure of a solid papillary growth pattern and a network of thick fibrovascular cores among proliferating atypical malignant cells. c Positive immunohistochemical staining findings for the estrogen receptor. Positive immunohistochemical staining findings for the following markers demonstrate the neuroendocrine component of the tumor: $\mathbf{d}$ neuronspecific enolase, e chromogranin, and $\mathbf{f}$ synaptophysin. $\mathbf{g}$ Negative immunohistochemical staining for the myoepithelial marker p63 (a: $\times 4$, b- $\mathbf{g}$ $\times 20)$
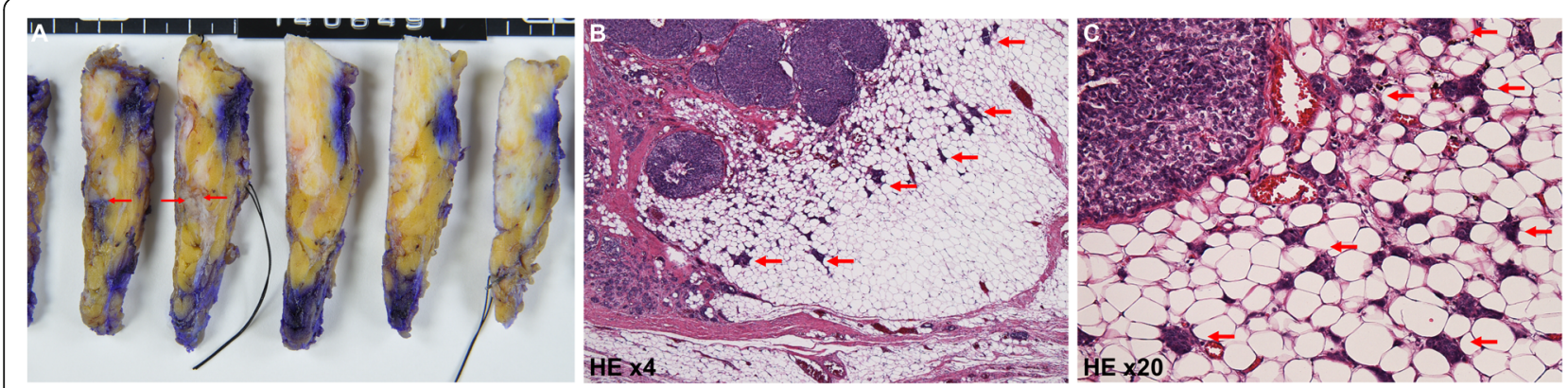

Fig. 3 Postoperative histological findings of the tumor. a Postoperative surgical specimen of the left breast tissue with a visible tumor (red arrow). b HE-stained section of the tumor at $\times 4$ magnification. $\mathbf{c ~ H E}$-stained section of the tumor at $\times 20$ magnification. The HE-stained sections illustrate a clear infiltration that suggests an invasive solid papillary carcinoma. The invasive components that spread out from the solid structure are visible (red arrow, b, c) 
appeared in the whole-body CT images 5 months after starting the treatment (Fig. $4 \mathrm{a}-\mathrm{c}$ ). We talked with the patient carefully about the merits and drawbacks of other treatments including chemotherapy, and the patient decided to undergo oral 5-FU treatment as the first-line chemotherapy. One year after the start of oral 5-FU treatment (S-1: $100 \mathrm{mg} /$ body/day, 2 weeks on 1 week off), the lung metastases disappeared, and the sizes of liver metastases were significantly reduced in size (Fig. $4 \mathrm{~d}-\mathrm{f}$ ). At present, the patient has taken the same dose of oral 5-FU treatment continuously for 2.5 years. No serious adverse events have been observed, and her quality of life (QOL) during the treatment currently appears to be favorable, more than 5 years after surgery.

\section{Discussion}

SPC is an uncommon breast tumor that is usually detected in postmenopausal women between 60 and 80 years of age $[2,4,9,10]$. In the described case, the patient was a 46-year-old premenopausal woman. In previously published literature, only $5.8 \%(9 / 156)$ of patients were premenopausal when SPC was diagnosed (Table 1); thus, the current SPC case is considered to be relatively unusual.

SPC originates from the ductal epithelium, and previously, studies have reported that the SPC tumor size ranges from less than 10 to $150 \mathrm{~mm}[1-3,6,24]$. Macroscopically, the tumors can be solitary or multiple and are well-circumscribed, nodular, and soft masses with hemorrhagic and cystic components. A gelatinous appearance may be grossly appreciated in tumors with mucinous differentiation $[2,4,9]$. Microscopically, SPC appears as proliferative nodules, each representing a duct filled with neoplastic proliferative components [2] The components can be either ovoid or spindle-shaped and are rarely stream-like in appearance, similar to ductal hyperplasia [2, 6]. The tumor components grow in a solid pattern with an intermingled fibrovascular network [2, 3]. In addition, nuclear palisading and pseudorosette formation around capillary vessels are standard features $[2-4,6]$.

Approximately $50 \%$ of cases are associated with invasive carcinoma [2]. In previous studies, invasive components have been reported in $27.2-75 \%$ of cases $[4,6,9,28]$. The invasion can be multifocal and may have a pattern that is neuroendocrine-like, pure or mixed colloid, tubular, or invasive ductal but is rarely lobular $[2,6,28]$. SPC may also express one of the myoepithelial markers, including P63, $\alpha$-smooth muscle actin, and CD10, and the expression of the proliferative tumor marker Ki-67 is usually low (less than $10 \%)[6,10,28]$. Most SPCs show features of a low or intermediate nuclear grade, and a high nuclear grade is only reported in a few cases [6, 28-30].

In the diagnosis of SPC, classification as in situ or invasive lesions is recommended [28]. Different studies have shown that SPC lacks myoepithelial cells at the tumor nodule periphery $[2,6,9,11,24,29]$. In some studies, pathologists have routinely used the lack of peripheral myoepithelial cells to ascertain the invasion of papillary tumors, but this criterion is still controversial $[2,6]$. In general, the invasive carcinoma component is diagnosed when malignant cells are clearly present beyond the solid tumor nodules $[2,31]$.
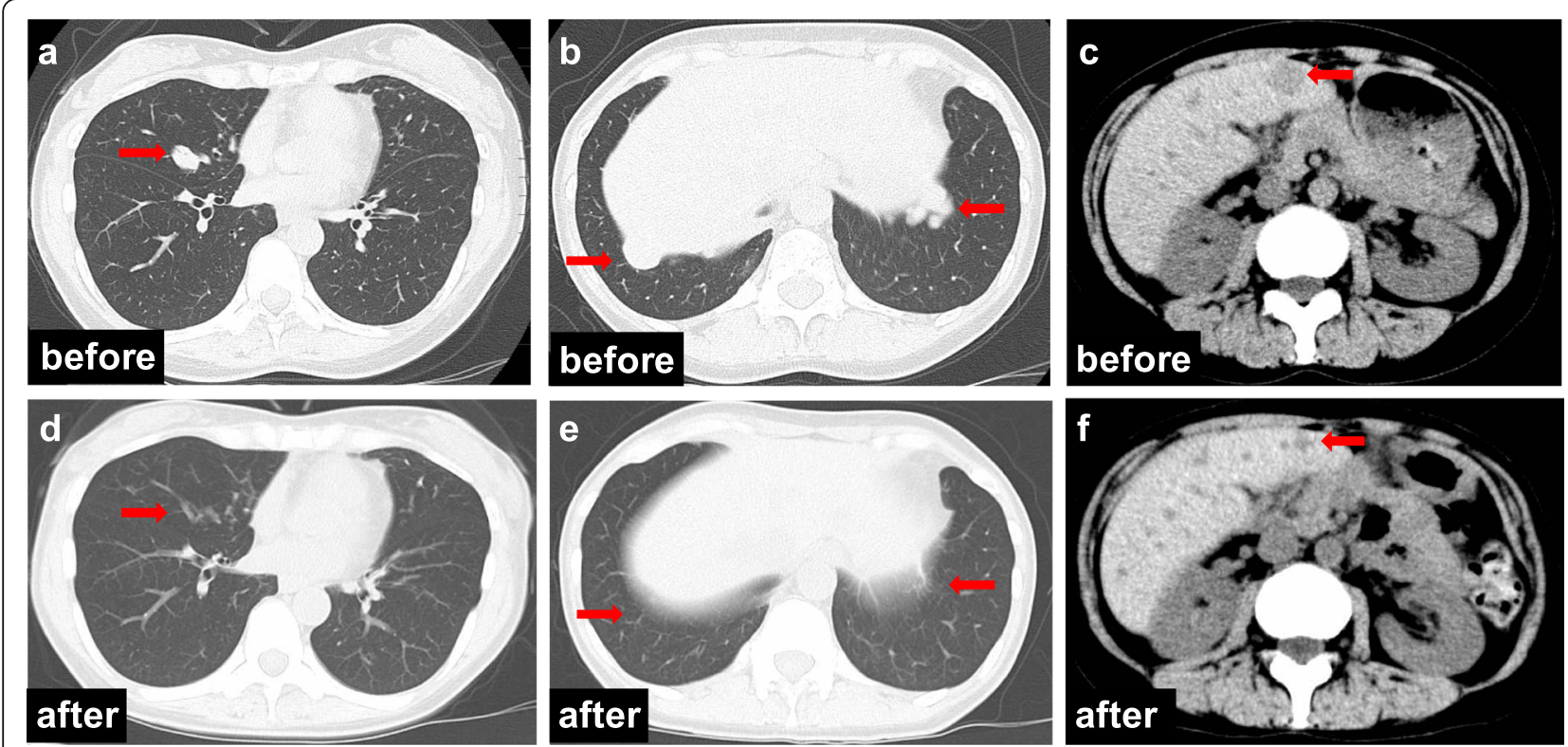

Fig. 4 Whole-body CT before and after chemotherapy. Lung metastatic nodules $(\mathbf{a}, \mathbf{b})$ and liver tumors (c) were detected. According to treatment with oral 5-FU, the lung metastatic tumors completely disappeared $(\mathbf{d}$, e), and the liver metastases remarkably regressed (f) 
Table 1 Previous reports of SPC

\begin{tabular}{|c|c|c|c|}
\hline Reference & Number of cases & $\%$ premenopausal $\left(\right.$ age $^{\mathrm{a}}$ ) & $\%$ of cases that showed distant metastasis \\
\hline Maluf and Koerner [3] & 20 & 0 & $5 \%$ \\
\hline Otsuki et al. [4] & 20 & $15 \%(31,45,48)$ & 0 \\
\hline Nassar et al. [6] & 58 & $1.7 \%(30)$ & $8.6 \%$ \\
\hline Nicolas et al. [11] & 11 & $9.1 \%(48)$ & 0 \\
\hline Foschini et al. [12] & 13 & $7.7 \%(48)$ & n.a. \\
\hline Eusebi et al. [13] & 5 & 0 & n.a. \\
\hline Tosi et al. [14] & 4 & $50 \%(45,47)$ & n.a. \\
\hline Cameselle et al. [15] & 1 & 0 & n.a. \\
\hline Chang et al. [16] & 1 & 0 & n.a. \\
\hline Masood et al. [17] & 1 & 0 & n.a. \\
\hline Colella et al. [18] & 1 & 0 & n.a. \\
\hline Chiang et al. [19] & 13 & 0 & n.a. \\
\hline Leena et al. [20] & 2 & $50 \%(44)$ & n.a. \\
\hline Zhang et al. [21] & 4 & 0 & n.a. \\
\hline Senel et al. [22] & 1 & 0 & n.a. \\
\hline Domoto et al. [23] & 1 & 0 & n.a. \\
\hline Rakha et al. [ 8] & 30 & n.a. & 0 \\
\hline Tsang and Chan [24] & 34 & n.a. & 0 \\
\hline Wei et al. [25] & 21 & n.a. & 0 \\
\hline Zheng et al. [26] & 32 & n.a. & $3.2 \%$ \\
\hline Zhong et al. [27] & 22 & n.a. & 0 \\
\hline Total & 295 & $5.8 \%^{\mathrm{b}}(9 / 156)$ & $2.8 \%^{\mathrm{b}}(7 / 248)$ \\
\hline
\end{tabular}

n.a not available

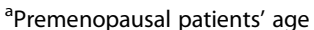

${ }^{b}$ The percentage data was calculated with the exception of n.a. cases

In the present case, the tumor size was determined microscopically and was $8 \mathrm{~mm} \times 7 \mathrm{~mm}$, and the tumor showed a solid, smooth margin against stromal tissue and a complete lack of staining of the myoepithelial markers at the periphery of the duct. Invasion was observed as irregularly shaped tumor nests that invaded the surrounding stroma, while the malignant cells were clearly spread out from the lobular unit of the adjacent SPC.

SPCs usually express a luminal phenotype $[4,6,9,29,30]$ and are positive for ER and PgR but are negative for HER2 $[2,6]$. The proliferation index is usually low, while SPCs are usually positive for neuroendocrine markers, including NSE, synaptophysin, and chromogranin, and negative for S100p and CD56 [2, 3, 6]. Neuroendocrine differentiation has been reported in approximately half of all SPC cases in the current literature $[4,6,9,28-30]$. It has been suggested that neuroendocrine differentiation might be a useful marker for the diagnosis of SPC [24, 29, 30]. However, not all SPC tumor cells exhibit neuroendocrine differentiation, and approximately $20 \%$ of invasive carcinomas of no special type also exhibit neuroendocrine differentiation. Therefore, neuroendocrine differentiation is clearly not necessary for the diagnosis of SPC $[4,29]$. In this case, in concordance with the published literature, the tumor was positive for ER receptor, negative for PgR receptor, and negative for HER2. Additionally, NSE, chromogranin, and synaptophysin were positive, but S-100p and CD56 were negative. Neuroendocrine differentiation should be assessed carefully in the diagnosis of invasive SPC, the clinical implication of which remains unknown. Bogina et al. [32] and Kwon et al. [33] investigated neuroendocrine differentiation in breast carcinoma (NDBC) compared to non-NDBC. The results revealed that patients with NDBC showed worse disease-free survival and overall survival compared to non-NDBC. Several researchers also highlighted the poor prognostic outcome of invasive NDBC, although the association remains uncertain $[28,30,34]$.

There are currently no evidence-based guidelines for the treatment of SPC, particularly for invasive disease, and as a result, the management of SPC is still controversial [8-10]. In invasive SPC, the prognosis may depend on the biological tumor features of the invasive component. Distant metastasis can be found without infiltration in the axillary lymph nodes $[2,6,8]$. Some authors have suggested that invasive SPC tumors are 
morphologically similar to SPC, but there is currently no clear evidence to ascertain whether the metastasis originates from the invasive SPC [1]. The management of SPC varies from breast-conserving surgery to mastectomy, while the role of SLNB is unclear. Axillary lymph node metastasis is thought to be present in approximately $3-5 \%$ of patients $[1,10]$. Retrospective analysis of previous studies on SPC showed that the frequency of distant metastases was approximately $2.8 \%$ (7/248) (Table 1).

In the present case, breast-conserving surgery, radiotherapy, and endocrine therapy were performed. Although there was no axillary lymph node involvement, this patient recurred with during adjuvant endocrine treatment, suggesting that the tumor would be hormone resistant. According to the anatomical stage and pathological findings, this patient was assessed as being at a low-intermediate risk of recurrence, but she developed metastases early. The mechanism of SPC metastasis is largely unknown [28], but as a speculation, luminal Blike features, PgR negativity, neuroendocrine differentiation, and a relatively young patient age may be associated $[28,30,32-35]$. As described, neuroendocrine differentiation shows a higher propensity for recurrence and poor overall survival [32-34].

Oral treatment with 5 -FU (S-1) was effective for this case. S-1 is well-tolerated, and its clinical usefulness has been shown in multiple trials [36-39]. Treatment with S-1 was feasible, and the QOL of this patient has been maintained for more than 2 years. Although these metronomic treatments might be efficient for invasive SPC, obviously, further studies are needed.

\section{Conclusions}

In conclusion, we reported a case of invasive neuroendocrine-differentiated SPC of the breast that developed in a premenopausal woman. Recurrence with multiple metastases occurred during adjuvant endocrine therapy, following which, an oral 5-FU was effective against the metastases. Invasive SPC remains rare, and its biological and clinical behaviors are largely unknown. Therefore, further investigations, with molecular analysis and accumulation of clinical experience, are warranted.

\footnotetext{
Abbreviations

SPC: Solid papillary carcinoma; N/C ratio: Nucleocytoplasmic ratio; SLNB: Sentinel lymph node biopsy; CNB: Core needle biopsy; ER: Estrogen receptor; PgR: Progesterone receptor; HER2: Human epidermal growth factor receptor 2; US: Ultrasonography; DCIS: Ductal carcinoma in situ; MRM: Modified radical mastectomy; NDBC: Neuroendocrine differentiation breast carcinoma; QOL: Quality of life; $\mathrm{GnRH}$ : Gonadotropin releasing hormone; 5-FU: 5-Fluorouracil; NSE: Neuron-specific enolase
}

Authors' contributions

$\mathrm{XL}$ wrote this paper. All authors contributed to the preparation of and approved the final manuscript.

\section{Funding}

This research did not receive any specific grant from funding agencies in the public, commercial, or not-for-profit sectors.

\section{Availability of data and materials \\ Not applicable.}

Ethics approval and consent to participate

Not applicable.

\section{Consent for publication}

Not applicable.

\section{Competing interests}

The authors declare that they have no competing interests.

\section{Author details}

${ }^{1}$ Department of Breast Surgery, Japanese Red Cross Wakayama Medical Center, 4-20 Komatsubara-dori, Wakayama 640-8558, Japan. ²Department of Breast Surgery, Kyoto University Hospital, 54 Kawaharacho, Syogoin, Sakyo-ku, Kyoto 606-8507, Japan. ${ }^{3}$ Department of Diagnostic Pathology, Japanese Red Cross Wakayama Medical Center, 4-20 Komatsubara-dori, Wakayama 640-8558, Japan. ${ }^{4}$ Department of Diagnostic Radiology, Japanese Red Cross Wakayama Medical Center, 4-20 Komatsubara-dori, Wakayama 640-8558, Japan.

Received: 26 January 2020 Accepted: 10 June 2020

Published online: 19 June 2020

\section{References}

1. Rakha EA, Ahmed MA, Ellis IO. Papillary carcinoma of the breast: diagnostic agreement and management implications. Histopathology. 2016;69:862-70.

2. Saremian J, Rosa M. Solid papillary carcinoma of the breast: a pathologically and clinically distinct breast tumor. Arch Pathol Lab Med. 2012;136:1308-11.

3. Maluf HM, Koerner FC. Solid papillary carcinoma of the breast. A form of intraductal carcinoma with endocrine differentiation frequently associated with mucinous carcinoma. Am J Surg Pathol. 1995;19:1237-44.

4. Otsuki Y, Yamada M, Shimizu S, Suwa K, Yoshida M, Tanioka F, et al. Solidpapillary carcinoma of the breast: clinicopathological study of 20 cases. Pathol Int. 2007;57:421-9.

5. Yamada M, Otsuki Y, Shimizu S, Tanioka F, Ogawa H, Kobayashi H. Cytological study of 20 cases of solid-papillary carcinoma of the breast. Diagn Cytopathol. 2007:35:417-22.

6. Nassar H, Qureshi H, Adsay NV, Visscher D. Clinicopathologic analysis of solid papillary carcinoma of the breast and associated invasive carcinomas. Am J Surg Pathol. 2006:30:501-7.

7. Wynveen CA, Nehhozina T, Akram M, Hassan M, Norton L, van Zee KJ, et al. Intracystic papillary carcinoma of the breast: an in situ or invasive tumor? Results of immunohistochemical analysis and clinical follow-up. Am J Surg Pathol. 2011:35:1-14.

8. Rakha EA, Gandhi N, Climent F, van Deurzen CH, Haider SA, Dunk L, et al. Encapsulated papillary carcinoma of the breast: an invasive tumor with excellent prognosis. Am J Surg Pathol. 2011;35:1093-103.

9. Guo S, Wang Y, Rohr J, Fan C, Li Q, Li X, et al. Solid papillary carcinoma of the breast: a special entity needs to be distinguished from conventional invasive carcinoma avoiding over-treatment. Breast. 2016;26:67-72.

10. Inno A, Bogina G, Turazza M, Bortesi L, Duranti S, Massocco A, et al. Neuroendocrine carcinoma of the breast: current evidence and future perspectives. Oncologist. 2016;21:28-32.

11. Nicolas MM, Wu Y, Middleton LP, Gilcrease MZ. Loss of myoepithelium is variable in solid papillary carcinoma of the breast. Histopathology. 2007;51: 657-65

12. Foschini MP, Asioli S, Foreid S, Cserni G, Ellis IO, Eusebi V, et al. Solid papillary breast carcinomas resembling the tall cell variant of papillary thyroid neoplasms: a unique invasive tumor with indolent behavior. Am J Surg Pathol. 2017:41:887-95. 
13. Eusebi V, Damiani S, Ellis IO, Azzopardi JG, Rosai J. Breast tumor resembling the tall cell variant of papillary thyroid carcinoma: report of 5 cases. Am J Surg Pathol. 2003;27:1114-8.

14. Tosi AL, Ragazzi M, Asioli S, Del Vecchio M, Cavalieri M, Eusebi LH, et al. Breast tumor resembling the tall cell variant of papillary thyroid carcinoma: report of 4 cases with evidence of malignant potential. Int J Surg Pathol. 2007;15:14-9.

15. Cameselle-Teijeiro J, Abdulkader I, Barreiro-Morandeira F, Ruiz-Ponte C, Reyes-Santias R, Chavez E, et al. Breast tumor resembling the tall cell variant of papillary thyroid carcinoma: a case report. Int J Surg Pathol. 2006;14:79-84.

16. Chang SY, Fleiszer DM, Mesurolle B, El Khoury M, Omeroglu A. Breast tumor resembling the tall cell variant of papillary thyroid carcinoma. Breast J. 2009; 15:531-5.

17. Masood S, Davis C, Kubik MJ. Changing the term "breast tumor resembling the tall cell variant thyroid of papillary carcinoma" to "tall cell variant of papillary breast carcinoma". Adv Anat Pathol. 2012;19:108-10.

18. Colella R, Guerriero A, Giansanti M, Sidoni A, Bellezza G. An additional case of breast tumor resembling the tall cell variant of papillary thyroid carcinoma. Int J Surg Pathol. 2015;23:217-20.

19. Chiang S, Weigelt B, Wen HC, Pareja F, Raghavendra A, Martelotto LG, et al. $\mathrm{IDH} 2$ mutations define a unique subtype of breast cancer with altered nuclear polarity. Cancer Res. 2016;76:7118-29.

20. JB L, Kini RG, Amber S. Invasive (solid) papillary carcinoma of the breast: a report of two cases. J Clin Diagn Res. 2013;7:1150-1.

21. Zhang L, Zhuang L, Shi C, Miao Y, Zhang W, Song Q, et al. A pilot evaluation of magnetic resonance imaging characteristics seen with solid papillary carcinomas of the breast in 4 patients. BMC Cancer. 2017;17:525.

22. Senel F, Karaman H, Eroglu M, Tuna O. Invasive papillary breast carcinoma, solid variant with neuroendocrine differentiation. Turk J Surg. 2017;33:302-4.

23. Domoto H, Watanabe A, Sakata M, Shimada A, Mukai K. Invasive solid papillary carcinoma of the nipple with pagetoid extension and nodal metastasis. Int J Surg Pathol. 2018;26:573-7.

24. Tsang WYW, Chan JKC. Endocrine ductal carcinoma in situ (E-DCIS) of the breast. Am J Surg Pathol. 1996;20:921-43.

25. Wei B, Bu H, Chen HJ, Zhang HY, Li XJ. Clinicopathological study of solid papillary carcinoma of breast. Zhonghua Bing Li Xue Za Zhi. 2006;35:589-93.

26. Zheng XC, Ge R, Meng LL, Liu CF. Clinicopathological study of solid papillary carcinoma in the breast. China Oncol. 2014:24:208-11.

27. Zhong DR, Sun PP, Liang ZY. Clinicopathological features of solid papillary carcinoma in breast. J Diag Path. 2010;17:165-8.

28. Tan PH, Schnitt SJ, van de Vijver MJ, Ellis IO, Lakhani SR. Papillary and neuroendocrine breast lesions: the WHO stance. Histopathology. 2015;66: 761-70.

29. Tariq MU, Idress R, Qureshi MB, Kayani N. Solid papillary carcinoma of breast; a detailed clinicopathological study of 65 cases of an uncommon breast neoplasm with literature review. Breast J. 2019;26:211-5.

30. Tan BY, Thike AA, Ellis IO, Tan PH. Clinicopathologic characteristics of solid papillary carcinoma of the breast. Am J Surg Pathol. 2016:40:1334-42.

31. Collins LC, Carlo VP, Hwang H, Barry TS, Gown AM, Schnitt SJ. Intracystic papillary carcinomas of the breast: a reevaluation using a panel of myoepithelial cell markers. Am J Surg Pathol. 2006;30:1002-7.

32. Bogina G, Munari E, Brunelli M, Bortesi L, Marconi M, Sommaggio M, et al. Neuroendocrine differentiation in breast carcinoma: clinicopathological features and outcome. Histopathology. 2016;68:422-32.

33. Kwon SY, Bae YK, Gu MJ, Choi JE, Kang SH, Lee SJ, et al. Neuroendocrine differentiation correlates with hormone receptor expression and decreased survival in patients with invasive breast carcinoma. Histopathology. 2013;64: 647-59.

34. Cloyd JM, Yang RL, Allison KH, Norton JA, Hernandez-Boussard T, Wapnir IL. Impact of histological subtype on long-term outcomes of neuroendocrine carcinoma of the breast. Breast Cancer Res Treat. 2014;148:637-44.

35. Ni YB, Tse GM. Pathological criteria and practical issues in papillary lesions of the breast- a review. Histopathology. 2016;68:22-32.

36. Saek T, Takashima S, Sano M, Horikoshi N, Miura S, Shimizu S, et al. A phase II study of S-1 in patients with metastatic breast cancer-a Japanese trial by the S-1 cooperative study group, breast cancer working group. Breast Cancer. 2004;11:194-202

37. Takashima T, Mukai H, Hara F, Matsubara N, Saito T, Takano T, et al. Taxanes versus S-1 as the first-line chemotherapy for metastatic breast cancer (SELECT BC): an open-label, non-inferiority, randomised phase 3 trial. Lancet Oncol. 2016;17:90-8.
38. Taira N, Aogi K, Ohsumi S, Takashima S, Nishimura R, Doihara H, et al. S-1 (TS-1) maintained complete response for approximately 10 years in a case of metastatic breast cancer. Breast Cancer. 2006;13:220-4.

39. Hirata K, Horikoshi N, Aiba K, Okazaki M, Denno R, Sasaki K, et al. Pharmacokinetic study of S-1, a novel oral fluorouracil antitumor drug. Clin Cancer Res. 1999:5:2000-5.

\section{Publisher's Note}

Springer Nature remains neutral with regard to jurisdictional claims in published maps and institutional affiliations.

\section{Submit your manuscript to a SpringerOpen ${ }^{\circ}$ journal and benefit from:}

- Convenient online submission

- Rigorous peer review

- Open access: articles freely available online

- High visibility within the field

- Retaining the copyright to your article

Submit your next manuscript at $\boldsymbol{\nabla}$ springeropen.com 